\title{
Increased myocardial blood flow during acute exposure to simulated altitudes
}

\author{
Philipp A. Kaufmann, MD, a Christian Schirlo, MD,c Vojtech Pavlicek, MD, ${ }^{c}$ \\ Thomas Berthold, a Cyrill Burger, PhD, b Gustav K. von Schulthess, MD, PhD, ${ }^{b}$ \\ Erwin A. Koller, MD, ${ }^{c}$ and Alfred Buck, $M^{a}$
}

\begin{abstract}
Background. Although only poor data exist on changes in myocardial blood flow (MBF) under acute hypoxia, patients with known coronary artery disease are advised not to exceed a moderate altitude exposure of about $2000 \mathrm{~m}$ above sea level.

Methods and Results. We measured MBF with positron emission tomography using O15-labeled water in 8 healthy human volunteers (aged $26 \pm 3$ years [mean \pm SD]) at baseline (450 $\mathrm{m}$ above sea level, Zurich, Switzerland) and during acute hypoxic hypoxemia induced by inhalation of 2 hypoxic gas mixtures corresponding to altitudes of 2000 and $4500 \mathrm{~m}$. MBF remained unchanged at $2000 \mathrm{~m}$ (increase of $10 \%$, not significant) but increased significantly at $4500 \mathrm{~m}$ $(62 \%, P<.001)$, exceeding the relative increase in rate pressure product.

Conclusions. Our results may explain why exposure to an altitude of $2000 \mathrm{~m}$ (corresponding to the cabin pressure in most airplanes during flight) is clinically well tolerated, even by patients with reduced coronary flow reserve, such as those with coronary artery disease. However, at an altitude of $4500 \mathrm{~m}, \mathrm{MBF}$ increases significantly, supporting the recommendation that patients with impaired flow reserve avoid exposure to higher altitudes. (J Nucl Cardiol 2001;8:158-64.)

Key Words: Myocardial blood flow $\bullet$ high altitudes • positron emission tomography
\end{abstract}

The inspiratory partial pressure of oxygen $\left(\mathrm{PIO}_{2}\right)$ at sea level is approximately $160 \mathrm{~mm} \mathrm{Hg}$. At altitudes of 2000 and $4500 \mathrm{~m}$ above sea level, the $\mathrm{PIO}_{2}$ is about 120 and $85 \mathrm{~mm} \mathrm{Hg}$, respectively. Concomitantly, in the alveolar air, $\mathrm{PO}_{2}$ is reduced to 75 and $55 \mathrm{~mm} \mathrm{Hg}$. In the healthy individual, the resulting hypoxemia causes a variety of respiratory, circulatory, and electrocardiographic (ECG) changes, ${ }^{1}$ including an increase in sympathetic tone, with pulmonary hypertension, hyperventilation, and an enhanced diuresis. The ECG changes have mainly been attributed to the synergistic effects of catecholamine secretion and vagal withdrawal rather than to direct hypoxic effects. ${ }^{2}$ In patients with marginal cardiocirculatory reserve or coronary artery disease (CAD), these

From the Departments of Nuclear Cardiology and Nuclear Medicine, ${ }^{\mathrm{b}}$ University Hospital and the Institute of Physiology, ${ }^{\mathrm{c}}$ University of Zurich, Zurich, Switzerland.

P.A.K. was funded by a grant from the Swiss National Science Foundation (SCORE B, grant no. 3232-055002.98).

Received for publication July 28, 2000; final revision accepted Oct 10, 2000.

Reprint requests: Philipp A. Kaufmann, MD, Cardiovascular Center, Nuclear Cardiology, University Hospital, Raemistr 100, CH-8091

Zurich, Switzerland; Philipp.Kaufmann@dmr.usz.ch.

Copyright $\odot 2001$ by the American Society of Nuclear Cardiology.

$1071-3581 / 2001 / \$ 35.00+0 \quad \mathbf{4 3 / 1 / 1 1 2 5 3 7}$

doi: $10.1067 / \mathrm{mnc} .2001 .112537$ effects may cause cardiac decompensation ${ }^{3}$ and silent ischemia during normal daily activities, even at a modest altitude of $2000 \mathrm{~m} .{ }^{4}$ Thus it is current clinical practice to advise patients with CAD not to exceed moderate altitudes of about 2000 to $2500 \mathrm{~m} . .^{5-7}$ Similar conditions are encountered in most airplanes during flight, raising some concerns about the risk of air travel for patients with CAD. 8,9

In experimental animals, acute hypoxemia ${ }^{10}$ and chronic hypoxemia have been shown to increase baseline ${ }^{11}$ and maximal drug-induced ${ }^{12}$ and exerciseinduced $^{11}$ myocardial blood flow (MBF). In contrast, only a few studies have examined the influence of acute hypoxic hypoxia on coronary circulation in human beings. A close relation between cardiac effort, myocardial oxygen consumption, and coronary flow has been repeatedly reported. ${ }^{13-15}$ Four decades ago, Gregg ${ }^{16}$ was the first to point out that most of the oxygen is normally removed from the coronary blood so that the oxygen content of coronary sinus (venous) blood cannot be reduced by very much. Therefore increased oxygen delivery must be achieved primarily by increased MBF. In fact, MBF is regulated to maintain constant myocardial tissue oxygen tension. ${ }^{17}$ However, Kaijser et al ${ }^{18}$ found an enhanced oxygen extraction at rest during acute exposure to an altitude of $2300 \mathrm{~m}$ and no change in MBF, which increased 
during physical exercise. Thus it remains unclear whether a reduced coronary vasodilator capacity (such as that in patients with $\mathrm{CAD}$ ) represents a risk factor during acute exposure to hypoxia.

The purpose of this study was to assess the influence of different stages of acute hypoxic hypoxia on MBF in healthy human volunteers.

\section{METHODS}

The study protocol was approved by the local ethics committee. Each volunteer gave informed written consent after the investigative nature of the study and its risks and merits had been carefully explained.

\section{Study Population}

We studied 8 healthy volunteers ( 1 woman and 7 men, aged $26 \pm 3$ years [mean \pm SD], range 23-32 years) who were nonacclimated (ie, they had no sojourn at or above $2700 \mathrm{~m} 4$ weeks before the experiment and were all living at altitude of Zurich, Switzerland). None of the subjects had a history of cardiovascular disease or smoking. Further inclusion criteria were normal heart rate, blood pressure, and electrocardiography and low probability of CAD development. ${ }^{19}$

\section{Study Protocol and Radiopharmaceuticals}

The simulation of altitude hypoxia (hypoxic hypoxia) was achieved by inhalation of moistened hypoxic gas mixtures (through a mouthpiece), consisting of approximately $17.5 \%$ and $12.5 \%$ oxygen in nitrogen, which correspond to altitudes of 2000 and $4500 \mathrm{~m}$, respectively. The 2 periods of hypoxic breathing were interposed by normoxic resting ventilation for 15 minutes. Heart rate and peripheral arterial oxygen saturation $\left(\mathrm{SaO}_{2}\right)$ were recorded with a finger pulse oximeter (Nellcor N-200E; Nellcor Inc, Hayward, Calif). Arterial blood pressure was measured by the oscillometric Riva-Rocci method with an upper arm cuff (Bosotron 2; Bosch \& Sohn, Jungingen, Germany). End-tidal partial pressure of carbon dioxide $\left(\mathrm{PEtCO}_{2}\right)$ and respiratory frequency were determined with a capnograph (Dräger Capnodig; Dräger, Lübeck, Germany).

At baseline 1 (450 m, Zurich), all volunteers breathed through a mouthpiece with occluded nasal airways to avoid confounding errors due to irritation by this installation. After a cardiorespiratory steady state was achieved, as assessed by a steady $\mathrm{PEtCO}_{2}, \mathrm{SaO}_{2}$, and heart rate, positron emission tomography (PET) measurements were performed after 15 minutes at baseline $1,2000 \mathrm{~m}$, and $4500 \mathrm{~m}$ and at the end of the experiment at baseline 2 (450 m, Zurich). By use of a bolus technique, 800 $\mathrm{MBq}$ of $\mathrm{O}-15-$ labeled water $\left(\left[{ }^{15} \mathrm{O} \mathrm{H}_{2} \mathrm{O}\right)\right.$ was injected into a peripheral vein of each volunteer at all of the above-mentioned conditions, while acquisition of the serial transaxial tomographic images of the heart was started. The 20 minutes between each $\left[{ }^{15} \mathrm{O}\right] \mathrm{H}_{2} \mathrm{O}$ injection allowed ample time for $\left[{ }^{15} \mathrm{O}\right]$ decay to occur (halftime $=2$ minutes). After the second baseline mea- surement, $350 \mathrm{MBq}$ of $\left[{ }^{13} \mathrm{~N}\right] \mathrm{ammonia}$ was injected for visualization of the myocardium to draw the regions of interest (ROIs) for quantitative analysis. Patient positioning for each image set was aided by marking the patient's chest with a felt-tip pen and aligning the marks with the reference laser beam of the tomograph.

\section{PET Protocol}

All images were acquired on a GE positron emission tomograph (GE Medical Systems, Milwaukee, Wis). This device records 35 image planes simultaneously. The axial field of view is $14.5 \mathrm{~cm}$. A 30 -minute blank scan was recorded as part of the daily routine procedures. Correct positioning of the volunteer's heart within the axial field of view of the tomograph was ascertained on a 4-minute rectilinear transmission scan. This was followed by a 20 -minute transmission scan for photon attenuation correction. Beginning with the intravenous administration of $\left[{ }^{15} \mathrm{O}\right] \mathrm{H}_{2} \mathrm{O}$, twelve 10 -second frames, four 30 -second frames, and one 60-second frame were recorded. Twelve-lead electrocardiograms were monitored continuously throughout the study. Heart rate and blood pressure were recorded at 1- and 5-minute intervals, respectively.

\section{Data Analysis}

Two representative midventricular slices were chosen from the acquired sets of 35 transaxial images for quantitative analysis. The images acquired after the ammonia injection were used to define a septal, anterior, and lateral ROI of the myocardial territory. ${ }^{20}$ Furthermore, a spheric ROI was placed in the blood pool of the left ventricle. All ROIs were then pasted to the dynamically acquired image sets. Myocardial and blood pool time-activity curves were generated from the dynamic frames and corrected for radioisotope decay.

\section{Estimates of MBF}

MBF was estimated by model fitting of the blood pool and myocardial time-activity curves. The PET-measured timeactivity curves were fitted with a 1-compartment model. ${ }^{21}$ $\mathrm{MBF}$ values for each ROI were calculated and averaged in each patient to create a mean MBF value for the entire myocardium. Because resting $\mathrm{MBF}$ is determined by cardiac workload, ${ }^{22}$ we also considered baseline MBF normalized for the rate pressure product (RPP), ${ }^{23}$ an index of myocardial oxygen consumption, by dividing MBF by RPP $\times 10^{-4}$ at each study condition for each patient.

\section{Statistical Analysis}

Values are given as mean $\pm \mathrm{SD}$, unless stated otherwise. Comparisons of hemodynamic and MBF values between the different study conditions were performed with analysis of variance statistics for repeated measures. If the $P$ value was below .05 , the Scheffé test was applied. 


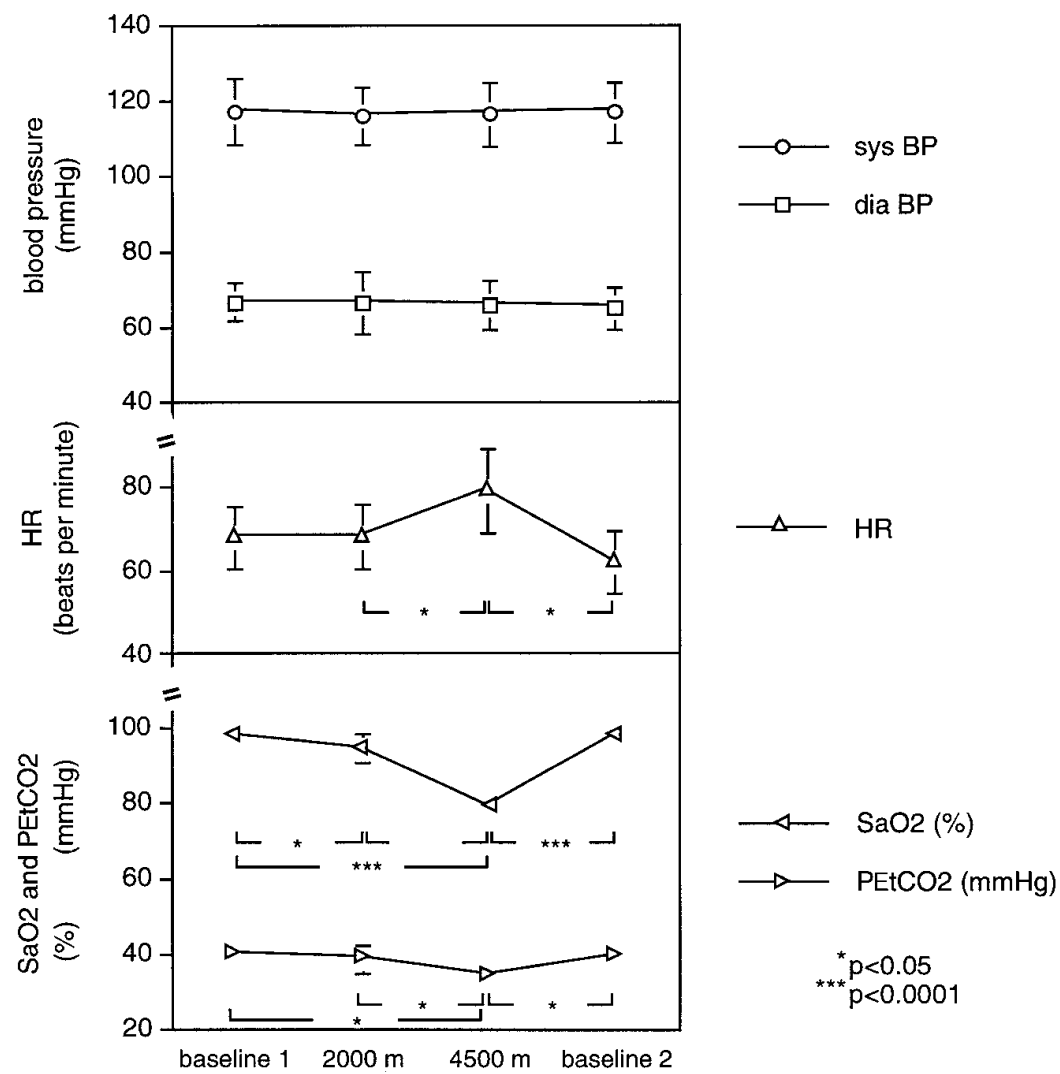

Figure 1. Hemodynamics and $\mathrm{SaO}_{2} / \mathrm{PEtCO}_{2}$. Although no significant changes were found for systolic and diastolic arterial blood pressure, heart rate increased significantly at $4500 \mathrm{~m}$ and was normalized after return to baseline. $\mathrm{PEtCO}_{2} \mathrm{was}$ similar at baseline and at $2000 \mathrm{~m}$ but decreased significantly at $4500 \mathrm{~m}$. SaO $\mathrm{S}_{2}$ decreased slightly at 2000 and $4500 \mathrm{~m}$ and was normalized after return to baseline. sys, Systolic; dia, diastolic; $B P$, blood pressure; $H R$, heart rate.

\section{RESULTS}

All subjects tolerated the simulated ascent to high altitude subjectively well and without major objective impairment.

\section{Hemodynamic and ECG Findings}

Heart rate was similar at baseline 1 ( $68 \pm 7$ beats $/ \mathrm{min})$ and $2000 \mathrm{~m}(68 \pm 9$ beats $/ \mathrm{min})$, increased at $4500 \mathrm{~m}(80 \pm$ 10 beats $/ \mathrm{min}, P<.05)$, and decreased at baseline $2(64 \pm 8$ beats/min). No significant changes were found for systolic and diastolic arterial blood pressure, which averaged $116 \pm$ $8 \mathrm{~mm} \mathrm{Hg}$ and $66 \pm 8 \mathrm{~mm} \mathrm{Hg}$, respectively, at all altitudes (Figure 1). No significant ST-segment depression and no arrhythmia were found in any subject.

\section{Respiratory Reactions}

$\mathrm{PEtcO}_{2}$ was $39 \pm 3 \mathrm{~mm} \mathrm{Hg}$ at baseline 1 and remained unchanged at $2000 \mathrm{~m}(38 \pm 4 \mathrm{~mm} \mathrm{Hg})$; it decreased significantly at $4500 \mathrm{~m}(34 \pm 4 \mathrm{~mm} \mathrm{Hg}, P<$ .05 vs baseline 1$). \mathrm{SaO}_{2}$ decreased from $97 \% \pm 1 \%$ at baseline 1 to $94 \% \pm 2 \%$ at $2000 \mathrm{~m}(P<.05)$ and $83 \% \pm$ $4 \%$ at $4500 \mathrm{~m}(P<.0001)$. The respiratory frequency was about $14 \pm 3$ breaths/min and remained constant.

\section{Myocardial Blood Flow}

Estimates of mean MBF were $0.97 \pm 0.21 \mathrm{~mL} / \mathrm{min} / \mathrm{g}$ at baseline 1 (Zurich, $450 \mathrm{~m}), 1.07 \pm 0.30 \mathrm{~mL} / \mathrm{min} / \mathrm{g}$ at $2000 \mathrm{~m}$ (not significant [NS]), $1.56 \pm 0.36 \mathrm{~mL} / \mathrm{min} / \mathrm{g}$ at $4500 \mathrm{~m}(P<.0001$ vs baseline 1 and vs $2000 \mathrm{~m})$, and $1.07 \pm 0.20 \mathrm{~mL} / \mathrm{min} / \mathrm{g}$ at baseline 2 (Table 1). Thus there was no significant change in MBF at $2000 \mathrm{~m}$ (increase of $10 \%, \mathrm{NS})$. In contrast, MBF increased significantly by $62 \%$ at $4500 \mathrm{~m}(P<.001)$ and decreased at baseline 2 (Figure 2). After normalization for the RPP, MBF averaged $1.34 \pm 0.44 \mathrm{~mL} / \mathrm{min} / \mathrm{g}$ at baseline $1,1.34 \pm 0.39$ $\mathrm{mL} / \mathrm{min} / \mathrm{g}$ at $2000 \mathrm{~m}, 1.74 \pm 0.48 \mathrm{~mL} / \mathrm{min} / \mathrm{g}$ at $4500 \mathrm{~m}$ $(P<.01$ vs baseline 1 and $2000 \mathrm{~m})$, and $1.43 \pm 0.49$ 


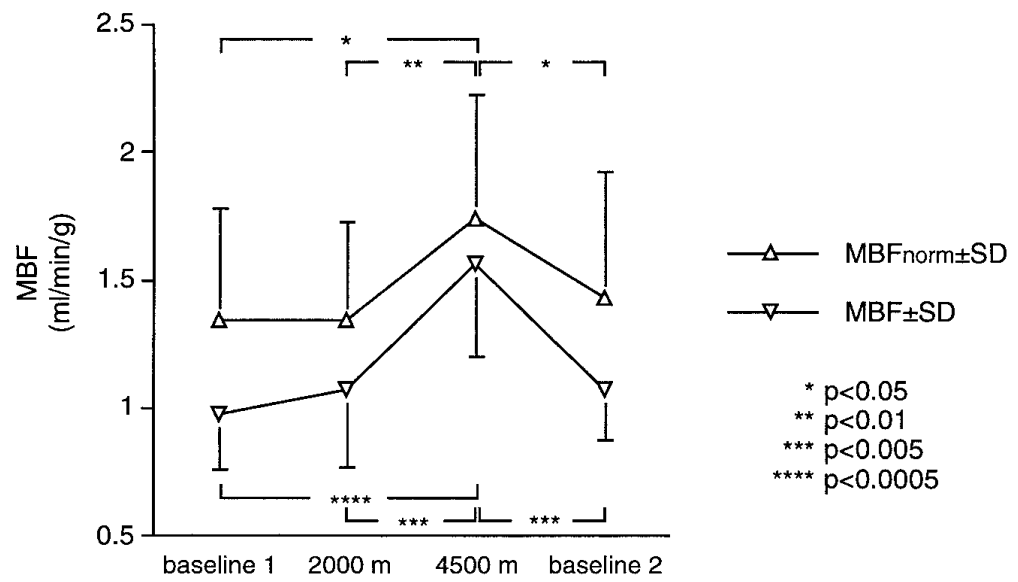

Figure 2. Influence of altitude on MBF. MBF did not change significantly at $2000 \mathrm{~m}$ but increased by $62 \%$ at $4500 \mathrm{~m}(P<$ .001 ) and decreased at baseline 2. After normalization for RPP, there was still a significant increase in blood flow (baseline MBF normalized [MBFnorm] 36\%, $P<.05$ ), indicating that the correlation between MBF and RPP does not hold at these conditions. This suggests that an important part of the MBF increase is due to direct hypoxia-induced vascular dilation.

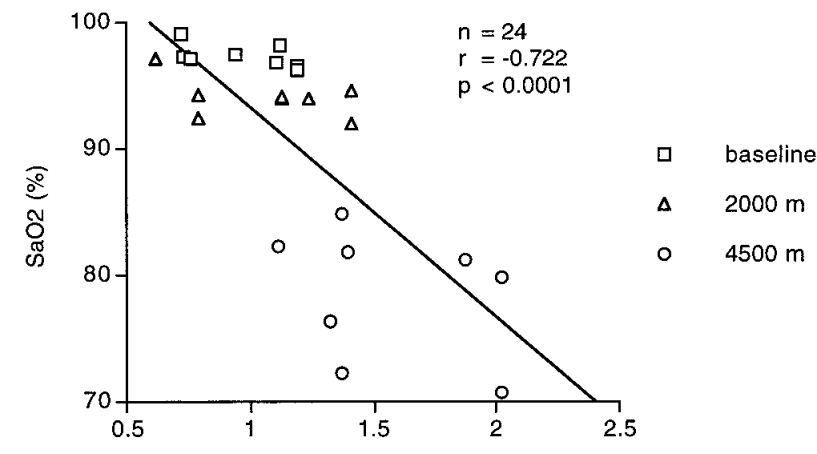

A

$\operatorname{MBF}(\mathrm{ml} / \mathrm{min} / \mathrm{g})$

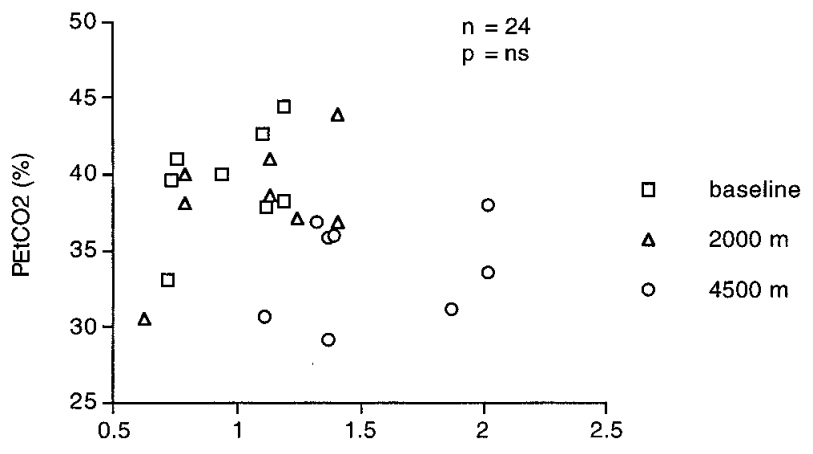

B

Figure 3. $\mathrm{MBF}$ was inversely correlated with $\mathrm{SaO}_{2}$ (an index of arteriolar $\mathrm{PO}_{2}$ ) (A) but not with $\mathrm{PEtCO}_{2}(\mathbf{B})$, supporting the theory that diminished oxygen tension may be the main stimulus for coronary dilation and that carbon dioxide plays a minor role at this altitude.

$\mathrm{mL} / \mathrm{min} / \mathrm{g}$ at baseline 2 (NS vs baseline 1). Thus, even after normalization of MBF for workload (ie, RPP), there was a significant increase in MBF at $4500 \mathrm{~m}(36 \%$, $P<.05)$ in excess of the increase in myocardial oxygen (Figure 2). In fact, the percentage increase in MBF at $4500 \mathrm{~m}$ was greater than the percentage increase in RPP $(62 \%$ vs $18 \%, P<.005)$. MBF was inversely correlated with $\mathrm{SaO}_{2}(r=-0.722, P<.0001)$, an extrapolated index of arteriolar $\mathrm{Po}_{2}$, but not with $\mathrm{PEtCO}_{2}$ (Figure 3).

\section{DISCUSSION}

In this study the changes in MBF during high-altitude exposure were assessed noninvasively by PET. In agreement with the findings of Grubbstrom et $\mathrm{al}^{24}$ and
Kaijser et al, ${ }^{18}$ our results show that there are no significant changes in MBF in healthy human beings at a moderate altitude of $2000 \mathrm{~m}$. This may explain the fact that even patients with CAD and impaired left ventricular function tolerate these conditions well, ${ }^{25}$ because no sizeable flow reserve seems to be required to meet the myocardial oxygen demand during the slight decrease in $\mathrm{PO}_{2}$ at $2000 \mathrm{~m}$. However, at high altitudes such as 4500 $\mathrm{m}$, an increase in MBF of $62 \%$ is observed despite the concomitant decrease in $\mathrm{PEtCO}_{2}$. A hypoxia-induced increase in heart rate due to sympathetic activation and vagal withdrawal could increase myocardial oxygen consumption because of an increase in cardiac work ${ }^{26}$ and thus could also account for increased MBF. ${ }^{27}$ There was still a significant increase in MBF $(36 \%, P<.05)$, how- 
Table 1. Myocardial blood flow (milliliters per minute per gram of tissue)

\begin{tabular}{lccccc}
\hline $\begin{array}{l}\text { Volunteer } \\
\text { No. }\end{array}$ & Baseline 1 & $\begin{array}{c}\text { Baseline1 } \\
\text { normalized }\end{array}$ & $\mathbf{2 0 0 0} \mathbf{~ m}$ & $\begin{array}{c}\mathbf{2 0 0 0} \mathbf{~ m} \\
\text { normalized }\end{array}$ & $\mathbf{4 5 0 0} \mathbf{~ m}$ \\
\hline 1 & 1.19 & 1.30 & 1.41 & 1.53 & 2.02 \\
2 & 1.10 & 1.33 & 1.13 & 1.14 & 1.32 \\
3 & 1.12 & 2.22 & 1.24 & 1.70 & 1.87 \\
4 & 0.94 & 1.17 & 1.13 & 1.34 & 1.39 \\
5 & 1.19 & 1.71 & 1.41 & 2.01 & 1.02 \\
6 & 0.72 & 0.88 & 0.62 & 1.00 & 1.37 \\
7 & 0.73 & 1.13 & 0.79 & 1.14 & 1.37 \\
8 & 0.76 & 0.94 & 0.79 & 0.86 & $1.56 \pm 0.36$ \\
Mean \pm SD & $0.97 \pm 0.21$ & $1.34 \pm 0.44$ & $1.07 \pm 0.30$ & $1.34 \pm 0.39$ &
\end{tabular}

Values are normalized for RPP, an index for workload.

ever, even after we accounted for the hypoxia-induced increase in workload by normalizing for RPP. This suggests that an important part of the MBF increase is due to direct, hypoxia-induced dilation. In fact, MBF was inversely correlated with $\mathrm{SaO}_{2}$ (an extrapolated index of $\mathrm{PaO}_{2}$ ) but not with $\mathrm{PEtCO}_{2}$ (Figure 3). This is in agreement with findings in experimental animals showing that diminished oxygen tension in the myocardium may be the main stimulus for coronary dilation ${ }^{28}$ and that carbon dioxide only plays a minor role at this altitude. ${ }^{27}$ The lack of significance in the MBF increase at $2000 \mathrm{~m}$, with a significant but slight decrease in $\mathrm{SaO}_{2}$, does not necessarily imply an increase in the oxygen extraction ratio. According to our findings, the decreasing arterial oxygen supply seems to be met by an autoregulatory increase of coronary flow, but the correlation between MBF and RPP no longer holds true under these conditions. In fact, this study, using a noninvasive technique, is the first full report describing an increase in MBF in human beings during acute hypoxic hypoxia, providing evidence for the assumed mechanism of coronary autoregulation. The exact nature of the coronary autoregulatory mechanism remains unclear because MBF is influenced by many factors. ${ }^{29}$ For example, chemoreceptor stimulation with neurogenic vasodilation mediated through vagal efferent fibers may occur during acute hypoxia. ${ }^{30}$

The oxygen deprivation at high altitudes can be tolerated only because of the increase in ventilation, which defends the alveolar $\mathrm{PO}_{2}$ against the reduced $\mathrm{PIO}_{2}$. In agreement with previous findings ${ }^{31}$ the respiratory frequency remained unchanged during our experiment, indicating that the hyperventilation was due to an increase in tidal volume. Initially, the hyperventilation results in a low arterial $\mathrm{PCO}_{2}$, causing respiratory alkalosis. This increases the oxygen affinity of hemoglobin and accelerates the oxygen loading of the pulmonary capillary blood. Stamler et $\mathrm{al}^{32}$ recently found that deoxygenation induces an allosteric transition in $S$-nitrosohemoglobin, causing the release of a nitric oxide group, which relaxes the vessels to bring local blood flow in line with oxygen requirements. This mechanism could contribute to the MBF regulation. Furthermore, adenosine may play an important role in this context because, in vitro, its production is linked to myocardial $\mathrm{Po}_{2}{ }^{33,34}$ and the major stimulus for adenosine formation seems to be an imbalance between oxygen delivery and oxygen demand. ${ }^{35,36}$ Cardiac adenosine production has been reported in myocytes ${ }^{37}$ and in endothelial cells, $33,37,38$ and coronary as well as myocardial adenosine receptors have been isolated in vitro. ${ }^{39}$ This endothelium-mediated mechanism is potentially susceptible to harm by risk factors such as hypertension ${ }^{40}$ and hypercholesterolemia, ${ }^{41}$ which have been shown to cause endothelial dysfunction, even in the absence of angiographically detectable CAD. Future studies on the influence of hypoxia in these patients and those with CAD should provide more insight.

\section{Study Limitations}

Realignment to the transmission image to correct for subject motion, as reported by Hoh et al, ${ }^{42}$ was not performed. However, during MBF measurements at rest, little if any subject movement occurs ${ }^{43}$ because subject motion is most often due to side effects of potent vasodilators such as adenosine or dipyridamole, neither of which was used in this study. Furthermore, the subjects were fixed with thoracic elastic bands after they were placed in the PET scanner.

Irritation caused by breathing through the mouthpiece might have influenced the subjects' respiration, leading to an altered pattern of breathing and possible 


\section{$4500 \mathrm{~m}$} normalized

Baseline 2

Baseline 2 normalized

$\begin{array}{ccc}2.00 & 1.31 & 1.59 \\ 1.32 & 1.12 & 1.43 \\ 2.12 & 1.21 & 1.94 \\ 1.31 & 0.90 & 1.12 \\ 2.60 & 1.31 & 2.32 \\ 1.74 & 0.98 & 1.12 \\ 1.23 & 0.85 & 1.09 \\ 1.61 & 0.85 & 0.86 \\ 74 \pm 0.48 & 1.07 \pm 0.20 & 1.43 \pm 0.49\end{array}$

sympathetic activation due to discomfort. To minimize this effect, all measurements, including both baseline measurements, were performed in the same way (the mouthpiece and the noseclip in place). A habituation effect over the study time that could affect the reproducibility of repeated measures can most likely be excluded because no differences were found between baseline 1 and baseline 2 with regard to $\mathrm{MBF}, \mathrm{PEtCO}_{2}$, and $\mathrm{SaO}_{2}$.

The age range of the study population was lower than that of the typical CAD age group. However, no difference in the physiologic response to hypoxia over a wide age range from 8 to 83 years has been reported. ${ }^{44}$

No additional measurements were performed during hyperemia to assess flow reserve (hyperemic/baseline flow) because of ethical reasons (restricted amount of radioactivity). Thus no firm conclusion on the influence of hyperemia on the myocardial flow reserve can be drawn. However, there is no evidence to suggest that hypoxia would affect the ceiling of maximal hyperemic MBF usually achieved by vasodilators such as adenosine or dipyridamole. This leads to the conclusion that, in hypoxia, flow reserve might be reduced because basal MBF is increased with no change in maximal MBF.

\section{Conclusions}

Acute exposure to an altitude of $2000 \mathrm{~m}$ (corresponding to the cabin pressure in most airplanes during flight) induces no changes in MBF at rest. This might explain why these conditions are clinically well tolerated, even by patients with reduced coronary flow reserve, such as those with CAD. However, at an alti- tude of $4500 \mathrm{~m}, \mathrm{MBF}$ increases significantly at rest, suggesting that patients with reduced flow reserve as seen in CAD can generally travel safely to moderate altitudes but should avoid exposure to higher altitudes. Although the exact mechanism of the coronary autoregulation remains unclear, adenosine is likely to play an important role.

\section{References}

1. Laciga P, Koller EA. Respiratory, circulatory, and ECG changes during acute exposure to high altitude. J Appl Physiol 1976;41:159-67.

2. Koller EA, Drechsel S, Hess T, Macherel P, Boutellier U. Effects of atropine and propranolol on the respiratory, circulatory, and ECG responses to high altitude in man. Eur J Appl Physiol 1988;57: 163-72.

3. Lomazzi F, Gurtner HP. Staying at high altitudes and plane travel for heart patients [in German]. Schweiz Med Wochenschr 1981;111:618-24.

4. Volker K, Hoppe B, Krestin M, Rost R. Cross-country and downhill skiing in patients with myocardial infarct. Can silent ischemia be prevented by drug therapy? [in German]. Fortschr Med 1990;108:273-5.

5. Gemelli A. Some cardiological problems in high mountains. Correlation with humans in flight [in German]. Minerva Med 1980;71:1985-9.

6. Roach RC, Houston CS, Honigman B, et al. How well do older persons tolerate moderate altitude? West J Med 1995;162:32-6.

7. Alexander JK. Coronary problems associated with altitude and air travel. Cardiol Clin 1995;13:271-8.

8. Beighton PH, Richards PR. Cardiovascular disease in air travellers. $\mathrm{Br}$ Heart J 1968;30:367-72.

9. Skjenna OW, Evans JF, Moore MS, Thibeault C, Tucker AG. Helping patients travel by air. Can Med Assoc J 1991;144:287-93.

10. Manohar M, Parks CM, Busch MA, et al. Regional myocardial blood flow and coronary vascular reserve in unanesthetized young calves exposed to a simulated altitude of $3500 \mathrm{~m}$ for 8-10 weeks. Circ Res 1982;50:714-26.

11. Paridon SM, Bricker JT, Dreyer WJ, et al. The effects of hypoxemia on myocardial blood flow during exercise. Pediatr Res 1989;25:280-4.

12. Reller MD, Morton MJ, Giraud GD, Wu DE, Thornburg KL. Maximal myocardial blood flow is enhanced by chronic hypoxemia in late gestation fetal sheep. Am J Physiol 1992;263:H1327-9.

13. Korner PI. Circulatory adaptations in hypoxia. Physiol Rev 1959;39: 687-730.

14. Katz LM, Feinberg H. The relation of cardiac effort to myocardial oxygen consumption and coronary flow. Circ Res 1958;6:656-69.

15. Schrader J. Mechanisms of coronary circulation regulation [in German]. Z Kardiol 1984;2:41-6.

16. Gregg DW. Regulation of the collateral and coronary circulation of the heart. In: McMichael J, editor. Circulation. Oxford (UK): Blackwell Scientific Publications; 1958.

17. Grover RF, Lufschanowski R, Alexander JK. Alterations in the coronary circulation of man following ascent to 3,100 $\mathrm{m}$ altitude. J Appl Physiol 1976;41:832-8.

18. Kaijser L, Grubbstrom J, Berglund B. Coronary circulation in acute hypoxia. Clin Physiol 1990;10:259-63.

19. Diamond G, Forrester J. Analysis of probability as an aid in the clinica diagnosis of coronary artery disease. N Engl J Med 1979;300:1350-8.

20. Hutchins GD, Schwaiger M, Rosenspire KC, Krivokapich J, Schelbert $\mathrm{H}$, Kuhl DE. Noninvasive quantification of regional blood flow in the human heart using N-13 ammonia and dynamic positron emission tomographic imaging. J Am Coll Cardiol 1990;15:1032-42.

21. Iida H, Kanno I, Takahashi A, et al. Measurement of absolute myocar- 
dial blood flow with $\mathrm{H}_{2}{ }^{15} \mathrm{O}$ and dynamic positron-emission tomography. Strategy for quantification in relation to the partial-volume effect [published correction appears in Circulation 1988;78:1078]. Circulation 1988;78:104-15.

22. Camici P, Marraccini P, Marzilli M, et al. Coronary hemodynamics and myocardial metabolism during and after pacing stress in normal humans. Am J Physiol 1989;257:E309-17.

23. Uren NG, Melin JA, De BB, Wijns W, Baudhuin T, Camici PG. Relation between myocardial blood flow and the severity of coronary artery stenosis. N Engl J Med 1994;330:1782-8.

24. Grubbstrom J, Berglund B, Kaijser L. Myocardial blood flow and lactate metabolism at rest and during exercise with reduced arterial oxygen content. Acta Physiol Scand 1991;142:467-74.

25. Erdmann J, Sun KT, Masar P, Niederhauser H. Effects of exposure to altitude on men with coronary artery disease and impaired left ventricular function. Am J Cardiol 1998;81:266-70.

26. Czernin J, Muller P, Chan S, et al. Influence of age and hemodynamics on myocardial blood flow and flow reserve. Circulation 1993;88:62-9.

27. Rushmer RF. The coronary system. In: Rushmer RF, editor. Cardiovascular dynamics. 2nd ed. Philadelphia: Saunders; 1961. p. 218-9.

28. Wolpers HG, Hoeft A, Korb H, Lichtlen PR, Hellige G. Heterogeneity of myocardial blood flow under normal conditions and its dependence on arterial $\mathrm{Po}_{2}$. Am J Physiol 1990;258(2 Pt 2):H549-55.

29. Marcus ML. The coronary circulation in health and disease. New York: McGraw-Hill; 1983. p. 65-92.

30. Heistad DD, Abboud FM. Circulatory adjustments to hypoxia. Circulation 1980;61:463-70.

31. Koller EA, Lesniewska B, Bührer A, Bub A, Kohl J. The effects of acute altitude exposure in Swiss highlanders and lowlanders. Eur J Appl Physiol 1993;66:146-54.

32. Stamler JS, Jia L, Eu JP, et al. Blood flow regulation by $S$-nitrosohemoglobin in the physiological oxygen gradient. Science 1997; 276:2034-7.
33. Deussen A, Moser G, Schrader J. Contribution of coronary endothelial cells to cardiac adenosine production. Pflugers Arch 1986;406:608-14.

34. Smolenski RT, Schrader J, de Groot GH, Deussen A. Oxygen partial pressure and free intracellular adenosine of isolated cardiomyocytes. Am J Physiol 1991;260:C708-14.

35. Bardenheuer H, Schrader J. Supply-to-demand ratio for oxygen determines formation of adenosine by the heart. Am J Physiol 1986;250:H173-80.

36. Schrader J, Bardenheuer H, Orntyd J. Relationship between myocardial metabolism and coronary blood flow regulation. Cardiologia 1985; 30:915-8.

37. Deussen A, Lloyd HG, Schrader J. Contribution of $S$-adenosylhomocysteine to cardiac adenosine formation. J Mol Cell Cardiol 1989;21: $773-82$.

38. Kroll K, Schrader J, Piper HM, Henrich M. Release of adenosine and cyclic AMP from coronary endothelium in isolated guinea pig hearts: relation to coronary flow. Circ Res 1987;60:659-65.

39. Schrader J, Kroll K, Henrich M, Piper HM. Coronary and myocardial adenosine receptors. Biomed Biochim Acta 1987;46:S421-6.

40. Frielingsdorf J, Seiler C, Kaufmann P, Vassalli G, Suter T, Hess OM. Normalization of abnormal coronary vasomotion by calcium antagonists in patients with hypertension. Circulation 1996;93:1380-7.

41. Kaufmann PA, Frielingsdorf J, Mandinov L, Seiler C, Hug R, Hess OM. Reversal of abnormal coronary vasomotion by calcium antagonists in patients with hypercholesterolemia. Circulation 1998;97:1348-54.

42. Hoh CK, Dahlbom M, Harris G, et al. Automated iterative three-dimensional registration of positron emission tomography images. J Nucl Med 1993;34:2009-18.

43. Nitzsche EU, Choi Y, Czernin J, Hoh CK, Huang S, Schelbert HR Noninvasive quantification of myocardial blood flow in humans: a direct comparison of the [13N]ammonia and the [15O]water techniques. Circulation 1996;93:2000-6.

44. Veglio M, Maule S, Cametti G, Cogo A, Lussiana L, Madrigale G, et al. The effects of exposure to moderate altitude on cardiovascular autonomic function in normal subjects. Clin Auton Res 1999;9:123-7.

\section{RECEIVE TABLES OF CONTENTS BY E-MAIL}

To receive the tables of contents by e-mail, sign up through our Web site at

http://www.mosby.com/nuclcard

Choose E-mail Notification.

Simply type your e-mail address in the box and click the Subscribe button.

Alternatively, you may send an e-mail message to majordomo@mosby.com. Leave the subject line blank, and type the following as the body of your message:

\section{subscribe nuclcard_toc}

You will receive an e-mail to confirm that you have been added to the mailing list.

Note that TOC e-mails will be sent out when a new issue is posted to the Web site. 